\title{
IMPORTANCE OF KOSOVO DIASPORA IN ECONOMIC DEVELOPMENT
}

\author{
Prof. Asoc. Dr. Hamdi HOTI', \\ Prof. Ass. Dr. Rifat HOXHA ${ }^{2}$, Dr. Sc. Remzi AHMETI ${ }^{3}$ \\ Faculty of Economic, University of Prizren, Kosovo, \\ Faculty of Economic, University of Prizren, Kosovo,
}

\begin{abstract}
Diaspora has great importance in economic development of Kosovo, becuase today Diaspora its main contrubutor in economic development in our state and in social, culture, political and historical development, becuase diaspora all of the time it has contribute in building of Kosovo in every economic field and other social aspects. Therefore, increase of invesmtent from diaspora in Kosovo is key object for economic development, so it should be the main priority for our government.

Government of Republic of Kosovo should have serious approach in treating effectively and efficient of diaspora, and should make long term strategy for ensuring of better conditions, to make ideal conditions to invest in Kosovo in different fields.Different investments from diaspora, today require liberal politics and pragmatic and planned strategy development, drafting favorable legal rates for strategic investment in all of economic activities. Where such investment from diaspora present the mos effective way to create new opportunities for jobs and creating condition to increase and develop economic sustainable. Diaspora should stimulated to invest in Kosovo in different fields as in: education system, healthcare, tourism, hotel, energy, agruculture, farming, etc.A special importance have investment from diaspora and its specifically for Kosovo by taking into account condition in how it should be realised economic development.
\end{abstract}

Key words: Diaspora, Strategic management, Economic Development, remmitances.

\section{Entry}

Kosovo diaspor for the country, it gives continously economic, politics, and moral support. The typical example that shows importance of diaspora for development of Kosovo is sum of remmitances that diaspora sent in the country every year.

Importance of Diaspora for Economic development of Kosovo is undeniable and indispensable. Especially large diaspora such as Kosovo that contain a large part of direct foreing investment and for more they can be ready to invest more in conditions to discourage other investors. Every year hundred milions invests of diaspora enter in Kosovo economy. Increasing of investments

\footnotetext{
${ }^{1}$ Prof. Asoc. Dr. Hamdi HOTI, Faculty of Economics, University of Prizren, Prizren, Kosovo,hamdi_hoti@hotmail.com ${ }^{2}$ Prof. Ass. Dr. Rifat HOXHA, Faculty of Economics, University of Prizren, Prizren, Kosovo,rifati.hoxha@uni-prizren.com ${ }^{3}$ Dr. Sc. Remzi AHMETI, Business University College, Prishtinë.Remitex56@ hotmail.com
} 
from diaspora its key object for economik development, so, it should be priority of priorities for country government. Government of Kosovo should have serious access about diaspora and it should have long term project to offer better condition, in that way diaspora will invest in different fields in the country.So, diaspora is potential with multidimensional value for the country. Even though they are outside home country, it has been constantly treated as an inseparable part of Kosovo's culture and people.

Outside home country lives and operate over $800^{4}$ thousands members of diaspora ${ }^{5}$, but this number is increasing, taking into account that immigration is challenge almost in every country (family reunion, education, living standar).

Genesis of immigrations outside of home country it has happend in different phase, starting from 60 's, where in massive manner houndred and thousands family were subjected to ill-treatments, rape and discrimination from authorities of Serbia. Much of it in previous years has been placed in Turkey. Nowdays, Albanian community in this country it is belived is bigger that it present in statistics, but in abstence of updated statistics we still have no real figures. However, its very important to understand that a very large part today saves customs and language, and other part it is fully integrated, is assimilated in Turkish society. ${ }^{6}$

From that time, immigration has been continous characteristic of our society. With the exception of the postwar period, trends for immigrations, first, that was by persecution of Yugoslavia system for political reason, than economic reason, etc. In this viewpoint, the case of saving mother tongue and identity, and strengthening of relationship with diaspora its very important for Kosovar's citiziens, in that manner to avoid assimilation of this communities and it risk losing this part of society ${ }^{7}$. Diaspora, in general, its distributed accros the world, however, always it has has remained the best and most meaningful link between Kosovo and the countries where it operates and lives.Apart from the distribution mainly in Western countries, our diaspora characterizes its integration into the countries where they live and operate, especially younger generations who are born and grown from outside home, the most recent part of the country of origin. This factor is very good explanatory because part of the diaspora is active and the second and third generation are more disconnected from the country of origin, and this disconnect is more and more present. A large percentage of our diaspora is well integrated in the countries where they live and from this diaspora there is created enormous potential of human and economic capital, therefore integration of diaspora in the countries where it lives and operates is also an important aspect of the relationship interstate for our country, using diaspora as a mediator partner. Taking these indicators into account, the diaspora has multiple powers for many reasons, both in terms of human capital and economic capital. Therefore, the preservation and development of national identity has a special importance, both for the state and for the society of Kosovo. Fortunately, from what we see and from ongoing contacts with Diaspora members, we can conclude that the national identity is still preserved to a high degree in the first generations. However, in the second and third generations there is a trend of impoverishment of language and connections with the country of origin. Organizing mother tongue and culture education through the educational system could create opportunities for preserving national identity to a greater extent ${ }^{8}$.

\footnotetext{
${ }^{4}$ IOM Kosovo (2012), Need to add the link,

${ }^{5}$ Easy immigration profile 2017,

${ }^{6}$ Poject strategy for Diaspora pg. 6, 2019-2023 and Operation Plan 2019-2021,

${ }^{7}$ Poject strategy for Diaspora pg. 6, 2019-2023 and Operation Plan 2019-2021,

${ }^{8}$ Poject strategy for Diaspora pg. 6, 2019-2023 and Operation Plan 2019-2021,
} 


\section{Which is importance of Diaspora in Economic development in Kosovo}

Kosovo is the youngest country in the world, today still faces with a lot difficulties in different aspects of state of construction and economic.

Economic increase in Kosovo behave about $4 \%$ where country economic is based in import and we buy more and we sell less, local production its supported littlebit from state institutions of the country and the market its not ensured, and as well as providing few facilities to Kosovar producers.Kosovo has powefull Diaspora, and consequently the majority of the population lives with remmitances that Diaspora sent to them.Kosovo Economy still is faced with serious problems. Since the time of rapid and immediate development in the early post-war years of 1999, Kosovo's economy has had little or no progress.

Despite the fact that the level of donor assistance is still high, although this level of assistance has experienced a downward trend, and since 2001 Kosovo has had very little GDP growth, ie Gross Domestic Product (GDP), as well as and there was a non-movement of BPV per inhabitant ${ }^{9}$. Kosovo has youngest population in Europe, with population growth one of the fastest in Europe. To prevent further unemployment growth ${ }^{10}$.

Remittances are largely stimulating domestic consumption, which affects the deepening of imports and consequently the trade deficit.This view mainly sees Kosovo as a transit country for remittances, where diaspora money goes in, circulates for several months and then goes out of the country usually through the import of food products.Excepted of this, a large sum of money the diaspora invests in the property, where as a results, last years there is an increase in the demand for real estate purchase, this phenomenon has also affected the rise of prices for local citizens who live in Kosovo. Diaspora related financial transactions include remittances, travel expenses in Kosovo and international investments made or facilitated by members of the Diaspora. Given the Diaspora population as opposed to the resident population in Kosovo, the economic impact of these transactions is high in relation to domestic production of Kosovo and of great importance for Kosovo's international reserve inflows ${ }^{11}$.

Remittances strengthen demand for imported and domestic goods and services, raise prices and ultimately payrolls throughout the Kosovo economy, thus contributing to the Kosovo transition from economic recovery following the investment-inclusive and inclusive growth conflict, which is a prerequisite for human development ${ }^{12}$.Creating appropriate policies regarding immigration and Kosovo's diaspora status is key to boosting economic growth and reducing macroeconomic disproportion in Kosovo. Through the implementation of such policies, the diaspora could contribute more effectively to raising human and financial capital, increasing economic growth and creating new jobs in Kosovo ${ }^{13}$.Strategic objectives aim at empowering, facilitating and encouraging diaspora engagement in the socio-economic development of the country of origin. Within this objective, the strategy aims to promote, stimulate and co-operate with formal and informal economic platforms in different parts of the world. Also, this objective aims to provide mechanisms for knowledge transfer and exchange of experiences from the Diaspora and vice versa ${ }^{14}$.Labor migration and economic interaction with the Kosovar diaspora abroad have a profound impact on the economic and livelihoods of many individuals in Kosovo and this is not limited to the level of households.Economic coorporation with Kosovo Diaspora are deep and

\footnotetext{
${ }^{9}$ Diaspora and Immigration policies pg. 7, Forum 2015, December 2007 Prishtin

${ }^{10}$ Diaspora and Immigration policies pg. 15, Forum 2015, December 2007 Prishtin

${ }^{11}$ Diaspora and Immigration policies pg. 33, Forum 2015, December 2007 Prishtin

${ }^{12}$ Diaspora and Immigration policies pg. 33, Forum 2015, December 2007 Prishtin

${ }^{13}$ Diaspora and Immigration policies pg. 7, Forum 2015, December 2007 Prishtin

${ }^{14}$ Project strategy for Diaspora pg. 16, 2019-2023 and Operation Plan 2019-2021
} 
they strengtheining impact in macroeconomic development of Kosovo and in this manner of all Kosovar's ${ }^{15}$.

According data of Central Bank of Kosovo, shipments, which are mainly spent on consumption, amount to about 750 million euros a year. Capital investments, mostly in real estate, amount to 250 million and expenditures during their stay in Kosovo amount to 900 million per year. Given these, with this strategy, this large multidimensional capital of the diaspora is aimed at the overall development of the country, these investments, which benefit both the diaspora and Kosovo. Diaspora investments in the country are a very important factor in preserving the identity of young people in the diaspora and their connection with the homeland ${ }^{16}$.

Diaspora investments require planned policies and strategies, continuous improvements in the legal and institutional framework, improvement and modernization of the infrastructure and improvement of the business climate. These investments represent the most effective way to create new jobs and at the same time create conditions for sustainable economic growth. Almost, every diaspora member has high interes to invest in Kosovo in different fields such as: Healthcare, Agriculture, Farming, Energy, Toursim, Hotels.

\section{Diaspora remittances in Kosovo are one of the main sources of funding}

Remmitances from Diaspora, today present source that ensure social stable statement and this money mainly send in the most case in consumation of family and less for investments on business. Kosovo Diaspora today is the most powerfull promotor of economic development and raising of social welfare in Kosovo. It has been around for years 700 million euro Remmitances per year that impact in country stable.

In 2018, total value of remmitances from Diaspora was 730.5 million euro. Remmitances of Diaspora's, according to the delivery channels mostly sends from agencies for money transfer, followed by other channels of delivery and banks ${ }^{17}$.

While, accepted remmitances in Kosovo for 2017, which at the same time represent the largest category within the secondary income account, amounted to euro 759.2 million, representing an annual growth of $9.9 \%$. Remmitances in Kosovo come mainly from Germany and Swiss, country which sent from $39.9 \%$ respectively $22.5 \%$ of general accepted remmitances in Kosovo. A significant part of remmitances is accepted and from USA, namelu $7.0 \%$ of total remmitances ${ }^{18}$.

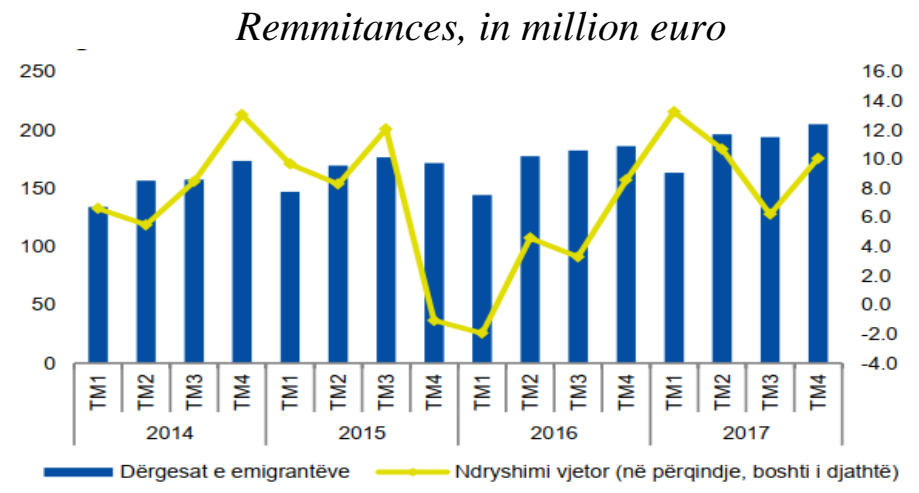

\footnotetext{
${ }^{15}$ Immigration as force for developmentpg. 12, Human Development Report in Kosovo 2014 Swiss Cooperation Office Kosovo

${ }^{16}$ Project Strategy for Diaspora pg. 10, 2019-2023 and Operation Plan 2019-2021

${ }^{17}$ Macroeconomic overview Ministry of Finance ASK and CBK 2018

${ }^{18} \mathrm{CBK}$ report for 2017, pg. 32, https://www.bqk-kos.org/
} 
Source: $C B K(2018)$

Accepted remmitances in Kosovo for 2016, hich at the same time presented the largest categorywithin the secondary income account, amounted to euro 691 million, which represents an annual growth of $3.8 \%{ }^{19}$.

\section{Analys Importance of Kosovo Diaspora in economic development}

In practical part of research and that what is role importance and what important role plays in Diaspora in economic development in the Republic of Kosovo through various forms is presented through a clear analysis which gives clear directions about the future which are the main forms to the implementation of the needs and forms of cooperation better with the diaspora for the development of Kosovo. In this online survey 161 respondent's that answer 12 question closely related to the subject, while the other two appear of information collectors in this part. In this survey are answered $62.1 \%$ from male gender and $37.9 \%$ female gender.

\section{Gender}

161 responses
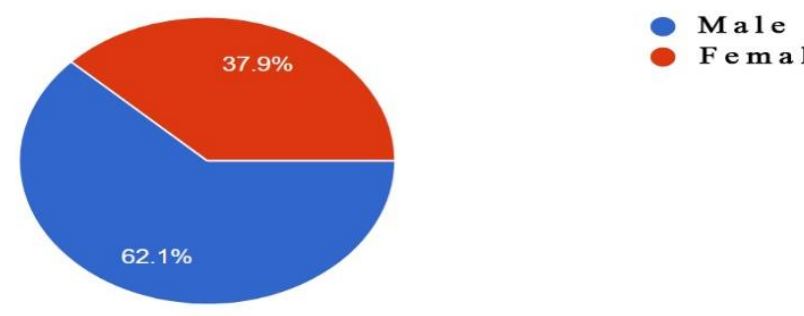

F e m a le

In the second part author's have decided to collect respondent of different age which are presented as three options and are as chronology assigned related with topic as below:

$\checkmark$ 20-35;

$\checkmark$ 35-45;

$\checkmark$ 45-65.

For first option in general are 161 respondents $60.9 \%$ are answered in survey those aged 20 to 35 years old, with $23.6 \%$ those from 45 to 65 years old from all respondents are answered $15.5 \%$ in aged 35 to 45 years old.

${ }^{19}$ Annual Report 2016, pg. 31, https://www.bqk-kos.org/. 


\section{Age}

161 responses

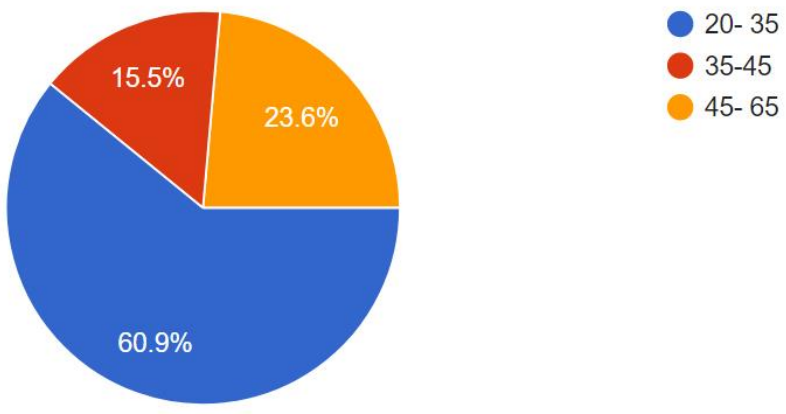

\section{Question 1:}

Research had aimed to extract importance of Diaspora's and its role in Kosovo, respondet's are answered question with $87.4 \%$ that have at least members of family outside of country and with $12.6 \%$ do not have anyone of family member.

\section{Do you have family members living abroad?}

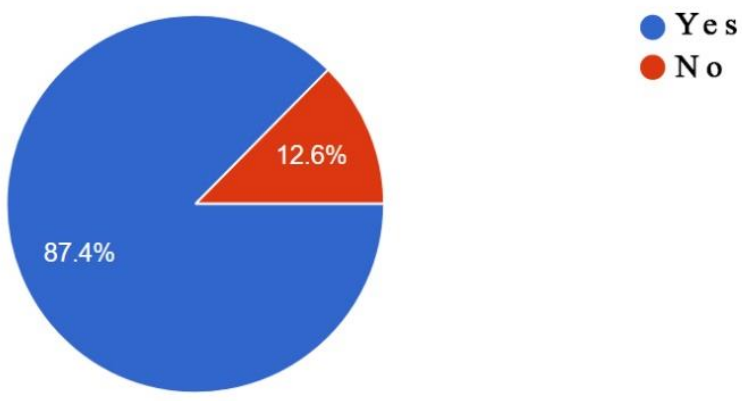

\section{Question 2:}

In second question related with the reason of leaving from Kosovo taking into account a lot of factors and circumstances in Kosovo as transition country and with no less importance in this phase, whereas answers/ research results for this question it gives interesting results over leaving the country, where $78.5 \%$ give reason if they go abroad from Kosovo they can have more opportunities for a better life, with $34.8 \%$ they think that they can find better opportunities for better education, $21.5 \%$ think for study reason, etc. 


\section{What are the reasons for leaving Kosovo?}

158 responses

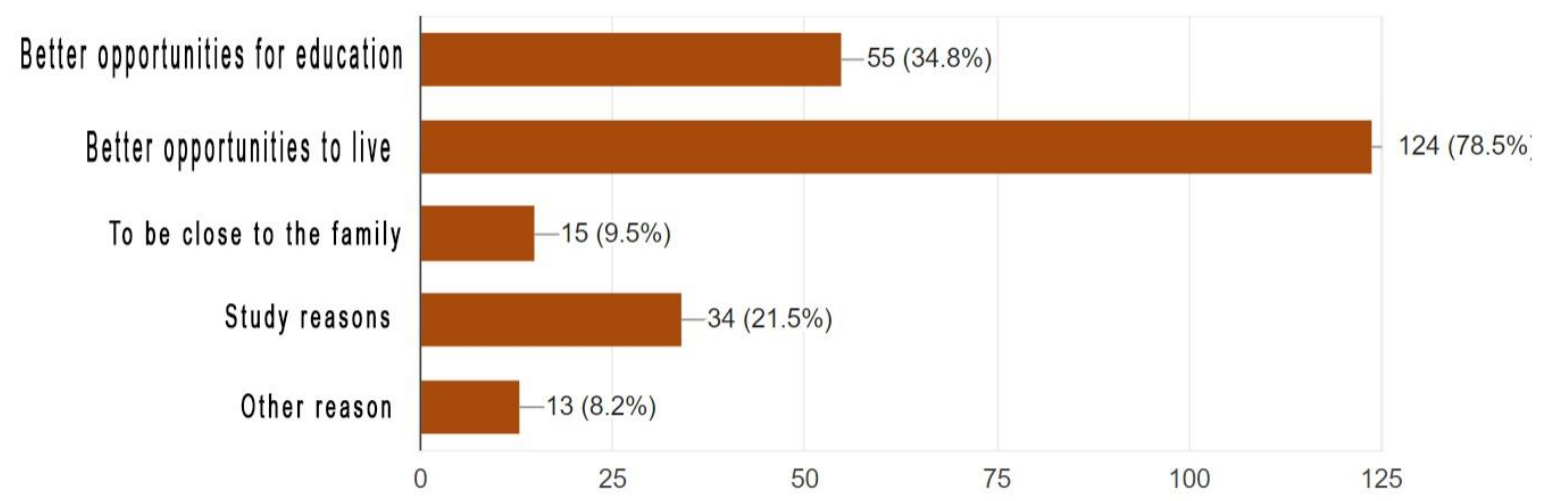

\section{Question 3:}

According a lot of research of scientific that have done for their forms and investments in Kosovo have given different results which leaves much to be desired. In this question, respondents with $46.3 \%$ think that investments in Kosovo made by Diaspora for emotional reason with hometown with $40.6 \%$ think for family reason and with $10 \%$ think for increasing and business development to operate in Kosovo.

3. What do you think, what they push to invest Diaspora in Kosovo?

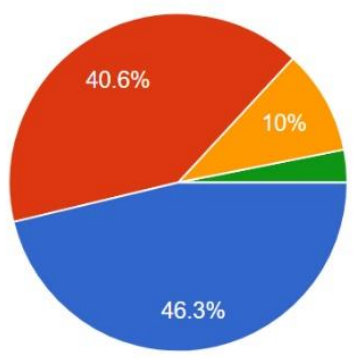

\section{Question 4:}

The issues raised try to give a solution to the question of the diaspora role for Kosovo, where fourth question require from respondents to give reason which present dependences of citizens of 
Kosovo from inputs of Diaspora. So with $29.4 \%$ responded that they are not at all dependent on these investments, $26.9 \%$ respond that they are very dependent on 19.4 think they are on average.

So, according to the reasoning of the diaspora respondents with their investments for a large part, they have no impact and are not dependent on their businesses, their having good income and other reasons, while the rest see themselves more dependent leaving a vacancy in that investments should be increased in order to stabilize the market and economy in the country.

4. How much are you dependent on the revenues coming from the diaspora?

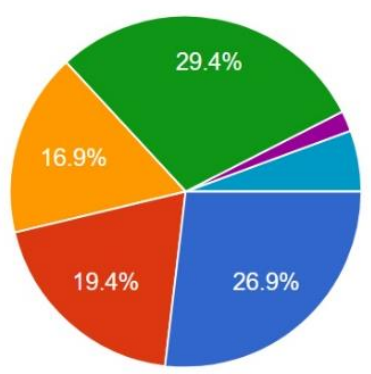

A lot of

- Average

Little

Not at all

- I do not know

- We do not have members of the family employed abroad.

\section{Pyetja 5:}

Investigations of Diaspora and their help through citizens that live in Kosovo according respondents is good, even are express as very satisfied with $36.1 \%$, while with $26.6 \%$ are moderately satisfied, and with $23.4 \%$ of respondents think that are relativety satisfied. This present that those investments excepts that have increase their impact they have improve living in Kosovo for family that help doing of daily obligation for a better life.

5. Do your family financially contribute and how satisfied are you with the support and assistance that is offered to you?

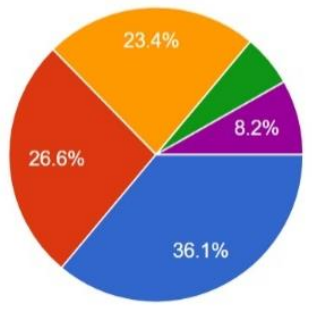

\section{Question 6:}


Different circumstances and reasons have pushed our nations together to invest in Kosovo and as such are referred to as diaspora investments, so according to the research we can see that $58.8 \%$ of respondents do not have any family members employed outside the Republic of Kosovo and they do not they have the idea and even the knowledge about Diaspora investments in the country that is primarily economic development is very doubtful. While $29.4 \%$ think that these investments are on average good and have a positive effect by raising the quality of the market economy.

6. Which is importance of Kosovo Diaspora in economic development of the country?

160 responses

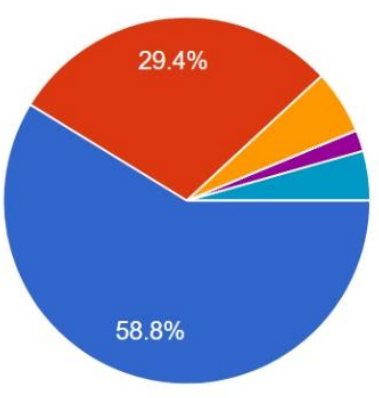

A lot of;

- Average;

Little;

Not at all;

I do not know;

We do not have members of the family emp

\section{Question 7:}

Bearing in mind development and development policies in the Balkans and beyond, of the 160 respondents surveyed think that diaspora is among the most important contribution of investment success in Kosovo, giving particular importance to this field, while $42.5 \%$ think that there are other forms of investment but also this is among the most important by agreeing on average.

7. It is Diaspora one of the most Important contributors of success for investments in Kosovo?

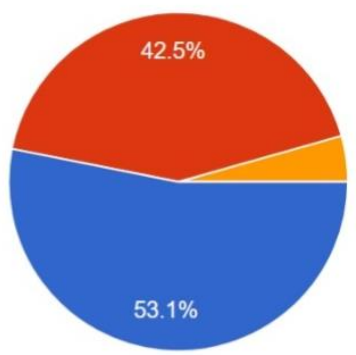




\section{Question 8:}

Any investment made in any given field gives rise to its impact, which has little or no negative or positive impact, so foreign investments (diaspora investments) in Kosovo have created a new logic of aid by facilitating many things. According to respondents, $34.4 \%$ think that the diaspora influence on economic development is high and is estimated at the same time for the citizens, with $32.5 \%$ think that the impact is very high and this support is expected to be even greater in the future while $31.3 \%$ of the respondents think that their influence is moderate.

8. Do you think the diaspora's influence on the economic development in Kosovo is high?

160 responses
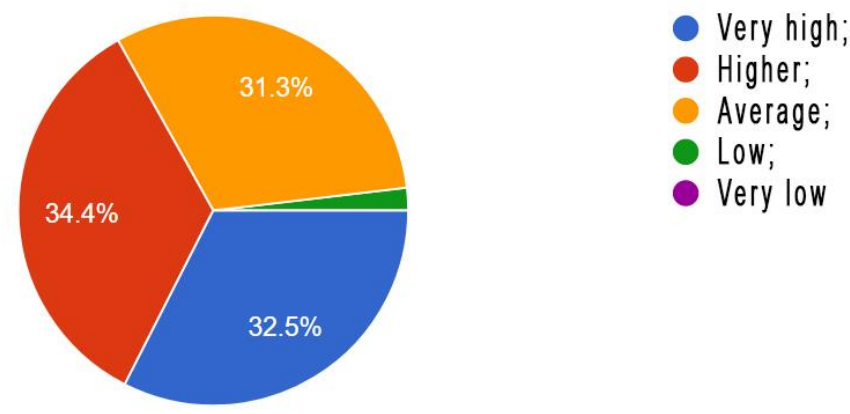

\section{Question 9:}

Considering the disturbance of the many citizens in this period in the Republic of Kosovo, it is necessary to take measures to create favorable conditions to regulate the situation and young people to work for their country, developing it in different forms and making it even stronger compared to economic competition and beyond. Considering many factors, respondent's responded with Yes $49.4 \%$, 32.5\% with No and $18.1 \%$ were shown as neutral.

9. Do you think that people should not leave their hometown?

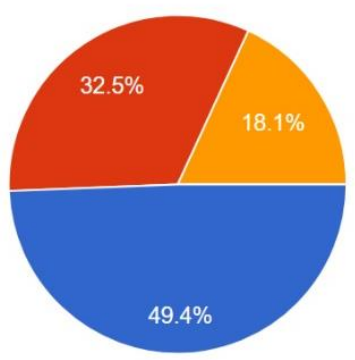

$$
\begin{aligned}
& \text { Yes; } \\
& \text { No; } \\
& \text { I don't know. }
\end{aligned}
$$




\section{Question 10:}

According to the respondents' responses, it is very disturbing to leave the citizens, which situation is also evidenced by the responses of respondents who with $49.1 \%$ answered positively that they would leave, with $26.4 \%$ not leaving and $20.1 \%$ responding with the option possibly leaving an opportunity to flee, but even in the case of improving economic and social conditions, they would stay in Kosovo.

11. Is the diaspora arrival in Kosovo well expected?

159 responses

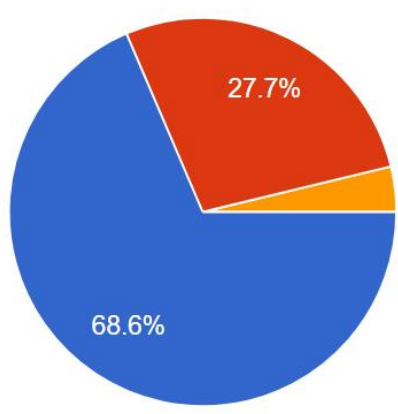

Always;

Usually;

Rarely;

Never.

\section{Question 12:}

Our comrades, besides having the reasons for the investments and the growth of the economic situation in Kosovo, have other reasons for the visit in Kosovo and the authors have established a number of them where the reason for family ties was chosen with $90.6 \%$, then with $33.1 \%$ reason for country respite, $3.8 \%$ for work, and $3.1 \%$ for different reasons they visit our country and theirs. 
12. What do you think, which are reason's of visiting of Diaspora's in Kosovo and no other countries?

160 responses

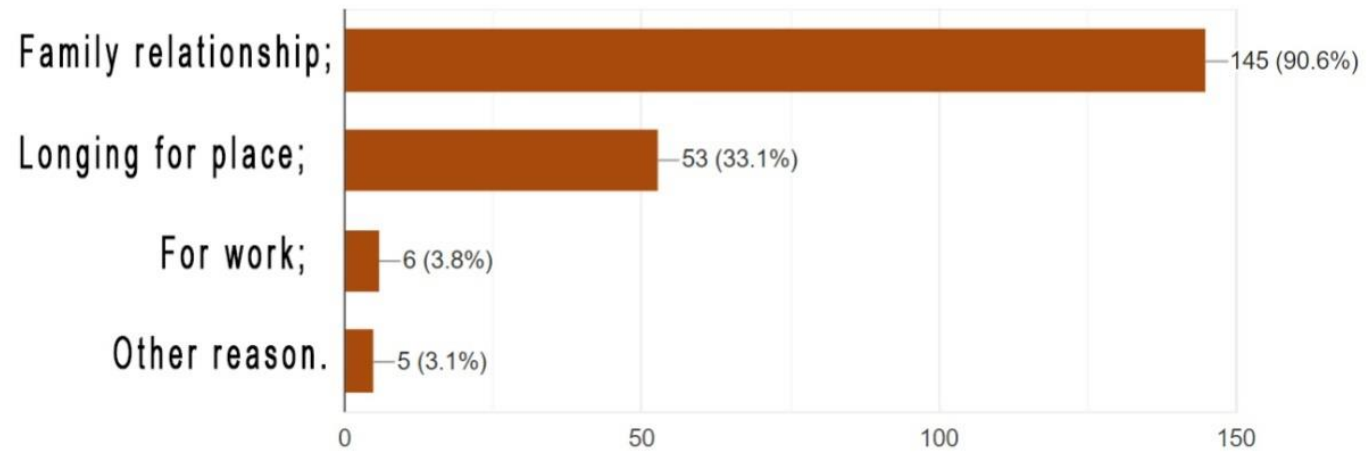

\section{Conclusion and Recommendation}

\section{Conclusion}

Diaspora's contribute through remmitances in Kosovo according assessments has been very large for postwar years to the present day with their investments, even though the state of Kosovo should make the drafting of institutional strategies for the best use of the Diaspora and Kosovo connections for the realization of projects of national interest such as projects: health, education, energy, minerals, etc. Make greater engagement of Kosovar authorities in involving diaspora in decision-making on Kosovo development projects.

Deeper cooperation between diaspora and local associations of Kosovo to exchange their experiences and knowledge in different fields of business. All this would contribute to sending remittances from abroad to greater sustainability towards Kosovo's development, and to alleviate unemployment in Kosovo, which is currently very high where there is still employment potential through investments. In the future it is expected that the level of remittances will be further reduced, where one of the main reasons for the decline of remittances from the Diaspora is the reunification of families with their members, as well as the employment of family members in Kosovo.

\section{Recommendations}

Since the post-war, remittances from the diaspora have played a very important role in Kosovo's economic development. The main recommendations for the diaspora role are for the country to develop a development strategy and to orient itself towards absorbing investment from the diaspora.The realization of this goal can be achieved by working in several directions: improving 
ISSN 2661-2666( Online) International Scientific Journal “Monte" DOI : $\underline{10.33807 / m o n t e .1 .201904231}$ ISSN 2661-264X (Print)

the investment climate in the country, improving the remittance transfer channels because a considerable part is brought to Kosovo through informal roads, orienting and utilizing the potential of investors in tourism and other economic areas for the purpose of opening up new jobs.

\section{Literature}

1. CBK report per years: $2018,2017,2016,2015,2014$;

2. Sekaran, U. 2003 Research methods for business: A skill building approach, New Jersey: John Wilez \& Sons,

3. Strategy for Diaspora 2013-2018;

4. UNDP studies: "Remmitances studies 2010" and "Studies over Remmitances 2012",

5. www.ask.rks-gov.net;

6. Kosovo Statistical Agency (2017): Economic Statistics;

7. Diaspora and policies of immigration Forum 2015 December 2007 Prishtin;

8. Border Police Data, at the Ministry of Internal Affairs. (2013).Internet website of MIA;

9. Results of Survey of enumerators for Importance of Kosovar's diaspora in Economic developmentof country in 2019;

10. The Kosovo Human Development Report 2014;

11. European Commission (2017): EU Candidate and Pre-Accession Countries; Economic Quarterly 3, Economic and Financial Affairs;

12. International Monetary Fund (2017): World Economic Outlook, WOE Database;

13. International Monetary Fund (2017): World Economic Outlook, WOE Report;

14. http://ask.rks-gov.net/media/1379/migrimi-kosovar-2014.pdf.

15. IOM Kosovo (2012), Need to add the link,

16. Immigration easy profile 2017 ,

17. Project strategy for Diasporapg. 6, 2019-2023 and Operate Plan 2019-2021,

18. Diaspora and Migration Policiespg. 7, Forum2015, December 2007 Prishtin; 